
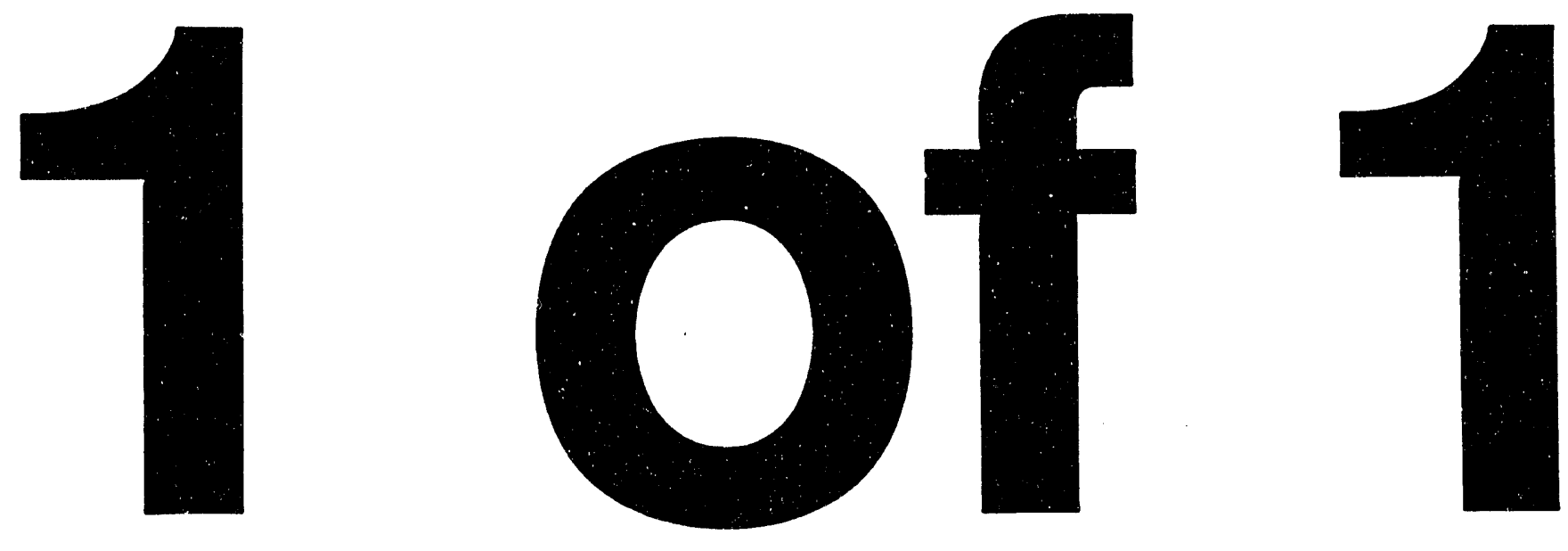


\title{
Conf-940815
}

PNL-SA-23466

\section{RADIOCHEMISTRY METHODS IN DOE METHODS FOR EVALUATING ENVIRONMENTAL AND WASTE MANAGEMENT SAMPLES}

\author{
S. K. Fadeff \\ S. C. Goheen
}

August 1994

Presented at the

Spectrum '94: International Nuclear and Hazardous

Waste Management Conference

August 14-18, 1994

Atlanta, Georgia

Prepared for

the U.S. Department of Energy

under Contract DE-AC06-76RLO 1830

Pacific Northwest Laboratory

Richland, Washington 99352

\section{DISCLAIMER}

This report was prepared as an account of work sponsored by an agency of the United States This report was prepared as an account of work sponsored by an agency thereof, nor any of their Government. Neither the United States Government nor any agency therest, ility or responsiemployees, makes any warranty, express or implied, or ans information, apparatus, product, or bility for the accuracy, completeness, or usefulness of any information, apparatus, product, Referprocess disclosed, or represents that its use would not infringe privately ownes trade name, trademark, ence herein to any specific commercial product, process, or service by trade ndorsement, recommanufacturer, or otherwise does not necessarily constitute or imply its endorsement, recome views mendation, or favoring by the United States Governmest or an state or reflect those of the and opinions of authors expressed herein do nof 


\title{
Radiochemistry Methods in DOE Methods For Evaluating Environmental And Waste Management Samples
}

\author{
SK Fadeff* and SC Goheen \\ Pacific Northwest Laboratory**, Richland, Washington 99352
}

\begin{abstract}
Current standard sources of radiochemistry methods are often inappropriate for use in evaluating U. S. Department of Energy environmental and waste management (DOE/EM) samples. Examples of current sources include EPA, ASTM, Standard Methods for the Examination of Water and Wastewater and HASL-300. Applicability of these methods is limited to specific matrices (usually water), radiation levels (usually environmental levels), and analytes (limited number). Radiochemistry methods in DOE Methods for Evaluating Environmental and Waste Management Samples (DOE Methods) attempt to fill the applicability gap that exists between standard methods and those needed for DOE/EM activities. The Radiochemistry chapter in DOE Methods includes an "analysis and reporting" guidance section as well as radiochemistry methods. A basis for identifying the DOE/EM radiochemistry needs is discussed. Within this needs framework, the applicability of standard methods and targeted new methods is identified. Sources of new methods (consolidated methods from DOE laboratories and submissions from individuals) and the methods review process will be discussed. The processes involved in generating consolidated methods and editing individually submitted methods will be compared.
\end{abstract}

DOE Methods is a living document and continues to expand by adding various kinds of methods. Radiochemistry methods are highlighted in this paper. DOE Methods is intended to be a resource for methods applicable to DOE/EM problems. Although it is intended to support DOE, the guidance and methods are not necessarily exclusive to DOE. The document is available at no cost through the Laboratory Management Division of DOE, Office of Technology Development.

\section{Introduction}

The United States Department cf Energy (DOE) is responsible for environmental restoration and waste management (EM) at its various sites (1). Samples taken to support EM activities encompass a large variety of matrices, ranging from non-radioactive well water samples, to soil columns contaminated with leaking tank waste, to highly radioactive tank waste (2). Analysis of these samples is often required to be conducted according to practices accepted by various federal, state, and local agencies (3). These agencies often require that analyses be conducted according to standard methods to ensure data comparability and consistency. Available standard methods (4-8), however, do not always meet the various EM project needs. The document, DOE Methods for Evaluating Environmental and Waste Management Samples (DOE Methods), is designed to fill that gap (9).

\section{Radiochemistry Support for DOE/EM Activities}

The purpose of DOE Methods is three-fold. It is intended to bridge the gap between standard methods and methods needed or applicable to EM activities. It also provides new technology for field use and accelerates regulatory acceptance of these methods ( $9 * * *$ others??**). Many of these new technologies result in analytical waste reduction and faster analysis times. Finally, the document eliminates unnecessary methods development costs by making applicable methods accessible to all facilities in a timely manner. 
In 1993, DOE/EM sampling and analysis method needs were estimated (10). The radiochemistry needs were defined at that time, but have been updated and are shown in Table 1, Radiochemistry Methods Needs List. The list includes Field and Laboratory analysis categories as well as subcategories of specific matrices (soil, aqueous, high level radioactivity, and organic). Various screening techniques are identified as well as isotope specific analyses. The identified needs are based largely on experience with EM activities at the Hanford site, waste classification guidelines given in 10CFR61, and input from scientists at other sites. (The letter " $X$ " in Table 1 is used to show a method is needed; specific method identifications are given in place of the " $\mathrm{X}$ " where applicable.)

Several sources of standard methods were reviewed for applicability to DOE/EM needs (4-8). These standard methods tend to be limited to the analysis of a few isotopes and water and soil matrices. Drinking water is well represented and soil is less well represented. These methods are also generally designed for low-level rather than high-level radioactive samples.

After a review of currently available methods, several needs stand out. In the sample preparation category, application of microwave digestion for radionuclides and sample preparation for volatile isotopes such as $129 \mathrm{I}$ are needed. In almost all categories, methods that produce less mixed hazardous waste are needed.

\section{Guidance}

The Radiochemistry section in DOE Methods includes a guidance chapter and analytical methods. The guidance chapter discusses very general considerations specific to radiochemical laboratories. It includes a definition section that is used to define specific terms as they relate to radiochemistry analyses. This includes, for example, the definition of decision level count rate and minimum detectable activity. General considerations are also discussed regarding instrument calibration. Data reporting guidelines are also provided.

Concepts from other parts of the DOE Methods document are intended to be integrated with the radiochemistry chapter. These include general guidance on quality assurance (QA) and quality control (QC), safety and waste handling, and the sampling and analysis plan. Use of the performance-based approach to application of methods and deviation from standard methods for sample analysis is encouraged (Appendix B of DOE Methods).

Methods

The number of radiochemistry methods has grown from 1 to 17 over the past 18 months. The methods are summarized Table 2.

Table 2. Radiochemistry Methods in DOE Methods (April 1994)

\begin{tabular}{|c|c|c|}
\hline $\begin{array}{l}\text { Method } \\
\text { Number }\end{array}$ & Title & Summary \\
\hline \multicolumn{3}{|c|}{ Field Screening Methods } \\
\hline RS 100 & $\begin{array}{l}\text { In-Situ Analysis of Gamma- } \\
\text { Ray Emitting Radionuclides by } \\
\text { Borehole Logging }\end{array}$ & $\begin{array}{l}\text { A calibrated gamma spectrometer is used to } \\
\text { measure and map the gamma-emitting isotope } \\
\text { distribution as a function of depth from the } \\
\text { surface. }\end{array}$ \\
\hline
\end{tabular}




\begin{tabular}{|c|c|c|}
\hline RP230 & $\begin{array}{l}\text { Iodine-129 Analysis in } \\
\text { Aqueous Solutions }\end{array}$ & $\begin{array}{l}\text { Iodine is isolated by repeat extractions and ion } \\
\text { exchange. Determination proceeds by gamma } \\
\text { counting } 129 \text { and gravimetric yield } \\
\text { determination or by neutron activation analysis } \\
\text { followed by counting } 130 \text { I where yield is } \\
\text { determined by } 1311 \text { tracer. }\end{array}$ \\
\hline RP300 & $\begin{array}{l}\text { Nickel-59 and Nickel- } 63 \\
\text { Determination in Aqueous } \\
\text { Samples }\end{array}$ & $\begin{array}{l}\text { Nickel is isolated using a dimethylglyoxime } \\
\text { precipitation column. Nickel-59 is determined } \\
\text { by LEPS, } 63 \mathrm{Ni} \text { is determined by LSC, and the } \\
\text { yield is determined by stable Ni recovery. }\end{array}$ \\
\hline RP330 & $\begin{array}{l}\text { Separation of Niobium for } \\
\text { Niobium-94 and Niobium-93m } \\
\text { Determination }\end{array}$ & $\begin{array}{l}\text { Niobium is isolated from a complex matrix by } \\
\text { precipitation of hydrated niobium pentoxide. } \\
\text { Counting and } \mathrm{X} \text {-ray counting, respectively; } \\
\text { yield is determined by the radiochemical tracer } \\
\text { recovery of } 95 \mathrm{Nb} \text {. }\end{array}$ \\
\hline RP500 & $\begin{array}{l}\text { Purification of Strontium in } \\
\text { Water Before Strontium- } \\
89 / \text { Strontium-90 Measurement }\end{array}$ & $\begin{array}{l}\text { Strontium is purified by use of an Eichrom } \\
\text { Sr-Spec }{ }^{\circledR} \text { column. Chemical yield is traced } \\
\text { radiochemically or gravimetrically. Several } \\
\text { initial volume reduction and follow-on } \\
\text { counting options are presented. }\end{array}$ \\
\hline RP501 & $\begin{array}{l}\text { Determination of Total } \\
\text { Radioactive Strontium in High- } \\
\text { Level Samples using Extraction } \\
\text { Chromatography }\end{array}$ & $\begin{array}{l}\text { Strontium is purified by use of an Eichrom } \\
\text { Sr-Spec }{ }^{\circledR} \text { column. Chemical yield is } \\
\text { determined with } 85 \mathrm{Sr} \text { tracer. Counting is } \\
\text { performed with gas proportional counters or by } \\
\text { LSC. Purification options are presented if high } \\
\text { amounts of } 137 \mathrm{Cs} \text { or Pu are expected. }\end{array}$ \\
\hline RP510 & $\begin{array}{l}\text { Determination of Strontium-90 } \\
\text { in Dissolved Environmental } \\
\text { Samples using Chelex-100 }\end{array}$ & $\begin{array}{l}\text { Strontium is purified in an aqueous sample by } \\
\text { carbonate precipitation followed by an iron- } \\
\text { hydroxide scavenge. After } 90 \mathrm{Y} \text { in-growth, the } \\
\text { Y fraction is purified using a Chelex-100 } \\
\text { column. Yttrium is eluted and mounted as the } \\
\text { oxalate for subsequent gas-flow proportional } \\
\text { counting. Yield is determined by } 85 \mathrm{~S} \text { - and } \\
\text { stable Y. }\end{array}$ \\
\hline RP520 & $\begin{array}{l}\text { Determination of Strontium-90 } \\
\text { in Soil, Water, and Filter } \\
\text { Samples }\end{array}$ & $\begin{array}{l}\text { Complete sample dissolution is accomplished } \\
\text { by fusion. Strontium is precipitated as the } \\
\text { sulfate. After suitable } 90 \mathrm{Y} \text { in-growth, } \mathrm{Y} \text { is } \\
\text { purified by a series of hydroxide and oxalate } \\
\text { precipitations. Yttrium oxalate is counted on a } \\
\text { gas-flow proportional counter. Yield is } \\
\text { determined by } 85 \mathrm{Sr} \text { and stable } \mathrm{Y} \text {. }\end{array}$ \\
\hline RP530 & $\begin{array}{l}\text { Determination of Selenium-79 } \\
\text { in Aqueous Samples }\end{array}$ & $\begin{array}{l}\text { Selenium is isolated using ion exchange and } \\
\text { precipitation techniques. The activity of } 79 \mathrm{Se} \\
\text { is determined by liquid scintillation counting } \\
\text { relative to a }{ }^{14} \mathrm{C} \text { calibration. Yield is } \\
\text { determined by the chemical recovery of stable } \\
\text { Se. }\end{array}$ \\
\hline
\end{tabular}




\begin{tabular}{|c|c|c|}
\hline RP550 & $\begin{array}{l}\text { Technetium-99 Analysis using } \\
\text { Extraction Chromatography }\end{array}$ & $\begin{array}{l}\text { Pertechnetate is purified on a TEVA } \cdot \mathrm{Spec}^{\circledR} \\
\text { column. The resin may be mixed with LSC } \\
\text { cocktail and counted by LSC or the Tc may be } \\
\text { eluted and measured by ICP/MS. }\end{array}$ \\
\hline RP580 & $\begin{array}{l}\text { Water Distillation from Soil and } \\
\text { Aqueous Matrices using a } \\
\text { Lachat Micro-Dist }{ }^{\mathrm{TM}} \text { System for } \\
\text { Tritium Determination }\end{array}$ & $\begin{array}{l}\text { Water from soil and aqueous matrices is } \\
\text { distilled using a Lachat tube. A sample of the } \\
\text { distillate is analyzed by LSC. }\end{array}$ \\
\hline RP710 & $\begin{array}{l}\text { Laboratory Method for Gross } \\
\text { Alpha and Beta Activity } \\
\text { Determination }\end{array}$ & $\begin{array}{l}\text { Samples are leached and oxidized if necessary, } \\
\text { and an appropriate aliquot is dried onto a } \\
\text { counting planchet. Samples are counted on a } \\
\text { gas-flow proportional counter. A discussion } \\
\text { of calibration-curve generation and cross-talk } \\
\text { correction is provided. }\end{array}$ \\
\hline RP720 & $\begin{array}{l}\text { Rapid Determination of Gross } \\
\text { Alpha, Gross Beta, and Gross } \\
\text { Tritium in Water using a Liquid } \\
\text { Scintillation Counter }\end{array}$ & $\begin{array}{l}\text { Spectral ranges for alpha, beta, and tritium are } \\
\text { established on a liquid scintillation counter. } \\
\text { Counting efficiencies are determined as a } \\
\text { function of quenching. Samples are added } \\
\text { directly to LSC cocktail and counted. }\end{array}$ \\
\hline RP730 & $\begin{array}{l}\text { Gross Gamma Screening for } \\
\text { Environmental Matrices }\end{array}$ & $\begin{array}{l}\text { Soils and waters are counted on a gamma } \\
\text { detector in a calibrated geometry. An average } \\
\text { efficiency is applied to the gross count rate to } \\
\text { determine the gross-gamma activity. }\end{array}$ \\
\hline \multicolumn{3}{|c|}{ Instrumentation Methods } \\
\hline RI010 & Gamma-Ray Spectrometry & $\begin{array}{l}\text { Gamma-emitting radionuclides are qualitatively } \\
\text { or quantitatively determined in aqueous, } \\
\text { geological, and vegetation samples with a } \\
\text { gamma spectrometer. }\end{array}$ \\
\hline RI100 & $\begin{array}{l}\text { Liquid Scintillation } \\
\text { Instrumentation Method }\end{array}$ & $\begin{array}{l}\text { General operating principles of liquid } \\
\text { scintillation counters are discussed, including } \\
\text { steps to construct a quench curve (efficiency } \\
\text { calibration) }\end{array}$ \\
\hline \multicolumn{3}{|c|}{ Surface Analysis } \\
\hline RA010 & $\begin{array}{l}\text { Method for Utilization of Alpha } \\
\text { Track Detectors for } \\
\text { Characterization of Gross Alpha } \\
\text { Emission from Indoor Surfaces }\end{array}$ & $\begin{array}{l}\text { A simple, inexpensive alpha-track detector is } \\
\text { placed on an indoor surface for a set amount of } \\
\text { time. The resulting damage track density on } \\
\text { the detector surface, using a suitable } \\
\text { calibration, is a measure of the alpha activity on } \\
\text { the sample surface. }\end{array}$ \\
\hline RA020 & $\begin{array}{l}\text { Method for Utilization of } \\
\text { Electret Ionization Chambers } \\
\text { for Characterization of Gross- } \\
\text { Alpha Emission from Indoor } \\
\text { Surfaces }\end{array}$ & $\begin{array}{l}\text { A simple, inexpensive electret ionization } \\
\text { chamber is placed in contact with a sample } \\
\text { surface. The rate of change of the electret } \\
\text { surface charge is a measure of alpha activity } \\
\text { using an appropriate calibration factor. }\end{array}$ \\
\hline
\end{tabular}


Some of the radiochemistry methods unique to DOE Methods that apply to DOE/EM activities include borehole logging (RS100), activated Ni determination (RP300), 79 Se determination (RP530), and gross alpha emission from indoor surfaces (RA010 and RA020). Other methods utilize new technologies that result in faster turn-around time and much smaller waste streams when compared to standard methods. These include 90Sr determination (RP500 and RP501) and ${ }^{99} \mathrm{Tc}$ analysis (RP550). In other cases, the methods represent alternatives in analytical approaches to analysis problems. All methods included in DOE Methods have been used on real EM samples.

\section{Method Incorporation Process}

Criteria for including methods in DOE Methods are three-fold: 1) the method must meet EM needs; 2) the method is not essentially a standard method; and 3 ) the method is formatted to the document specifications. Methods are received from several sources. Methods developed from Laboratory Management Division (LMD) funding constitute a significant source. Methods from individual contributors are sought based upon applicability of their work. Another source is method consolidation from procedures in the DOE Procedures Database.

The method-consolidation process is intended to produce a method that encompasses all nuances of similar analytical techniques used at the various DOE sites. The DOE Procedures Database is scanned for appropriate procedures. The "appropriateness" of a procedure may be determined by analyte and/or matrix and/or other factors. The procedures are then faxed or copied to the consolidator. The procedures are read, and notes are taken regarding the basic chemistry involved, applicable matrices, detection limits, bias, waste generated, special equipment/facility needs, time involved for the chemical analysis, comparability to standard methods, and similarity to other procedures as they are read. Based on the described parameters, specific procedures are categorized. Similar procedures that meet the criteria for DOE Methods are then consolidated. Consolidation generally begins by selecting one well-written procedure. Options are added to that procedure as extraction products of the other similar procedures. The consolidated method is then sent to the original procedure authors for concurrence and/or editorial comments. Quality control data are also petitioned if the chemistry is not significantly altered. If the method is significantly altered and/or contributing laboratories are unable to submit their QC data as support for the method, then the method is sent to National Air and Radiation Environmental Laboratory (NAREL) for validation studies.

The method consolidation process is ongoing. Only currently available procedures in the $D O E$ Procedures Database are accessible to the consolidator. Key lab managers are encouraged to provide new methods and method updates as they become available to the DOE Procedures Database. The published methods in DOE Methods can be expanded to include new options and new method-performance data. Therefore, the use and applicability of existing methods can be expanded.

After consolidation is complete, the method incorporation and review process is virtually identical to that of the individually contributed methods. The first stage is to produce a draft method for incorporation in DOE Methods. The method is reformatted as appropriate to meet document requirements. It then undergoes editing by the technical and document editors. A proof copy is sent to the original author(s) for concurrence. Method performance data and a peer review for a draft method are not required.

For a method to shed its draft status, several steps must be completed. The method is submitted for external peer review. The method review team is composed of volunteers representing a wide 
variety of disciplines within radiochemistry. Reviewers are from sites including (but not limited to) Los Alamos National Laboratory, Oak Ridge National Laboratory, Idaho National Engineering Laboratory, Westinghouse Savannah River Plant, Westinghouse Hanford, IT Corporation, and Barringer Laboratory. Reviewers have approximately 3 weeks to review each method. Received reviewer comments are then returned to the author for resolution. Each comment must be resolved to the satisfaction of the author and technical editor. Finally, the method must have incorporated a complete method-performance section. This entails an evaluation of precision, bias, and limit of detection for at least one applicable matrix. Once these criteria are satisfied, the method will be distributed as verified.

Credit is given to authors for methods published in DOE Methods. Method author(s) and the sponsoring laboratory are credited on each method if it is submitted as an individual contribution. Consolidated methods are credited using references to the standard operating procedures. The method consolidator is identified as well as all contributing procedures, authors of procedures, and originating facility.

\section{Future Growth of Radiochemistry Methods in DOE Methods}

The radiochemistry section of DOE Methods continues to grow with emphasis on meeting the needs identified in Table 1. Input to the guidance chapter and individual methods (draft and verified) is encouraged. Users are also encouraged to provide pertinent information, such as additional interferences and/or linitations as well as expanded matrix applicability and performance data. Comments and information will be forwarded to the chapter editor for resolution and incorporation.

Several new methods are likely to be added to the October 1994 issue. Four of these are

- $\quad$ RP280 Lead-210 in Water Using Extraction Chromatography

- RP800 Sequential Separation of Am and Pu By Extraction Chromatography

- RS110 Actinide Screen

- $\quad$ RS551 Technetium-99 Analysis Using Filter Membrane Extraction

Additional methods applicable to the intent of DOE Methods may be submitted at any time for potential inclusion in the document. DOE Methods is becoming a standard method reference for radiochemistry. With the addition of more radiochemistry methods, its applicability and usefulness to $\mathrm{DOE} / \mathrm{EM}$ activities is expanding.

\section{Conclusion}

DOE Methods is a useful source for radiochemistry methods. It is intended to supplement other standard radiochemistry methods. It is rapidly expanding and is responsive to users' comments/input. Regulatory acceptance is being sought. Our goal is to make DOE Methods help meet the needs of DOE/EM programs.

\section{References}

(1) US DOE Environmental Restoration and Waste Management Five-Year Plan 1992-1996. June 1990 
(2) Chemical Contaminants on DOE Lands and Selection of Contamination Mixtures for Subsurface Science Research, RG Riley, JM Zachara, FJ Wobber, DOE/ER-0547T, April 1992.

(3) Washington State Department of Ecology, United States Environmental Protection Agency and United States Department of Energy. 1994. Hanford Federal Facility Agreement and Consent Order. Fourth Amendment. 89-10 Rev. 3.

(4) U. S. Environmental Protection Agency (EPA). 1986. Test Methods for Evaluating Solid Waste: Volume 1B, Laboratory Manual Physical/Chemical Methods, 3rd Edition. EPA/SW846, Office of Solid Waste and Emergency Response, Washington, D. C. Available from National Technical Information Service, Springfield, Virginia.

(5) Prescribed Procedures for Measurement of Radioactivity in Drinking Water, EPA-600/480-032, Herman L. Krieger and Earl L. Whittaker, August 1980.

(6) Chieco, N. A., D. C. Bogen, and E. O. Knutson, Eds. 1990. Environmental Measurements Laboratory Procedures Manual, 27 Ed., HASL-300.

(7) American Society for Testing and Materials (ASTM)

(8) Standard Methods for the Examination of Water and Wastewater, Arnold E. Greenberg, Lenore S. Clesceri, Andrew D. Eaton, eds., 18th Edition, 1992.

(9) 1992, Goheen, S. C., et al., DOE Methods Guidance, Environmental Testing and Analysis, Nov/Dec 1992, Vol. 1, Num. 6.

(10) 1993, Goheen, S. C., et al., Needed Sampling and Analytical Methods for the Document DOE Methods for Evaluating Environmental and Waste Management Samples, Mixed Waste: Proceedings of the Second International Symposium, Baltimore, MD, pp 8.1.1-8.1.9.

Krieger, H. L. and E. L. Whittaker. Prescribed Procedures for Measurement of Radioactivity in Drinking Water. EPA-600/4-80-032.

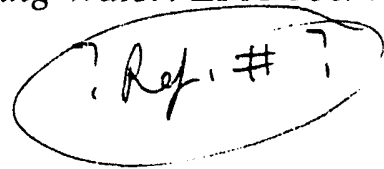



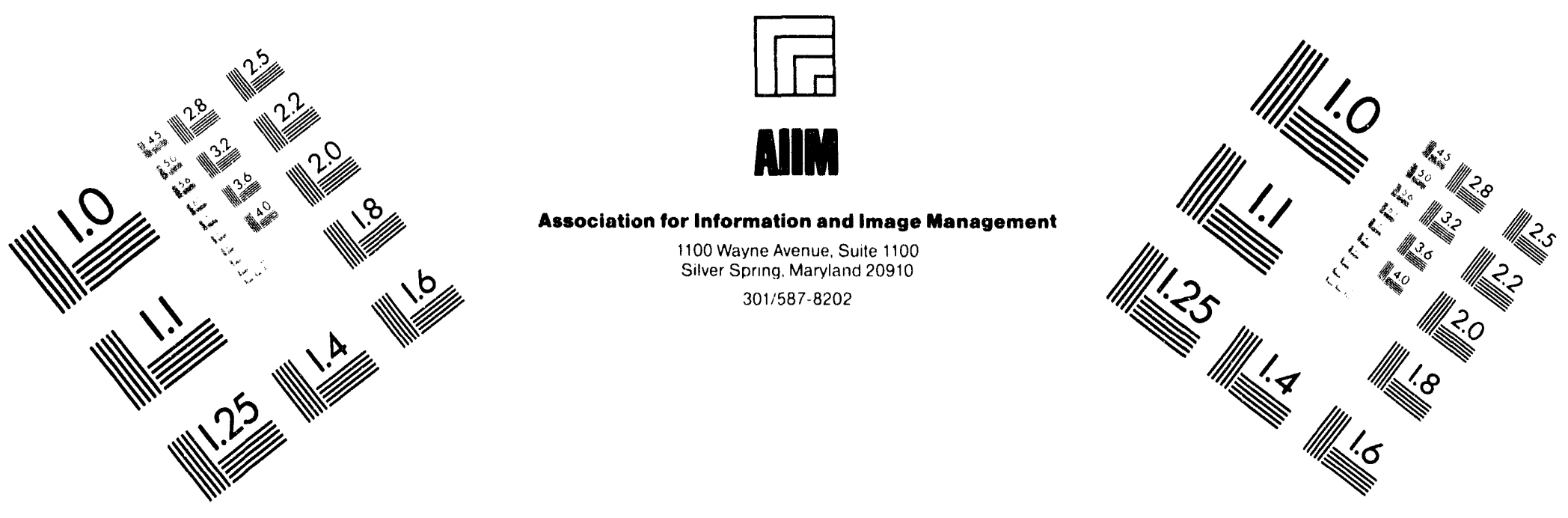

\section{Centimeter}

$\mid \begin{aligned} & 1 \\ & \mid\end{aligned}$ Inches
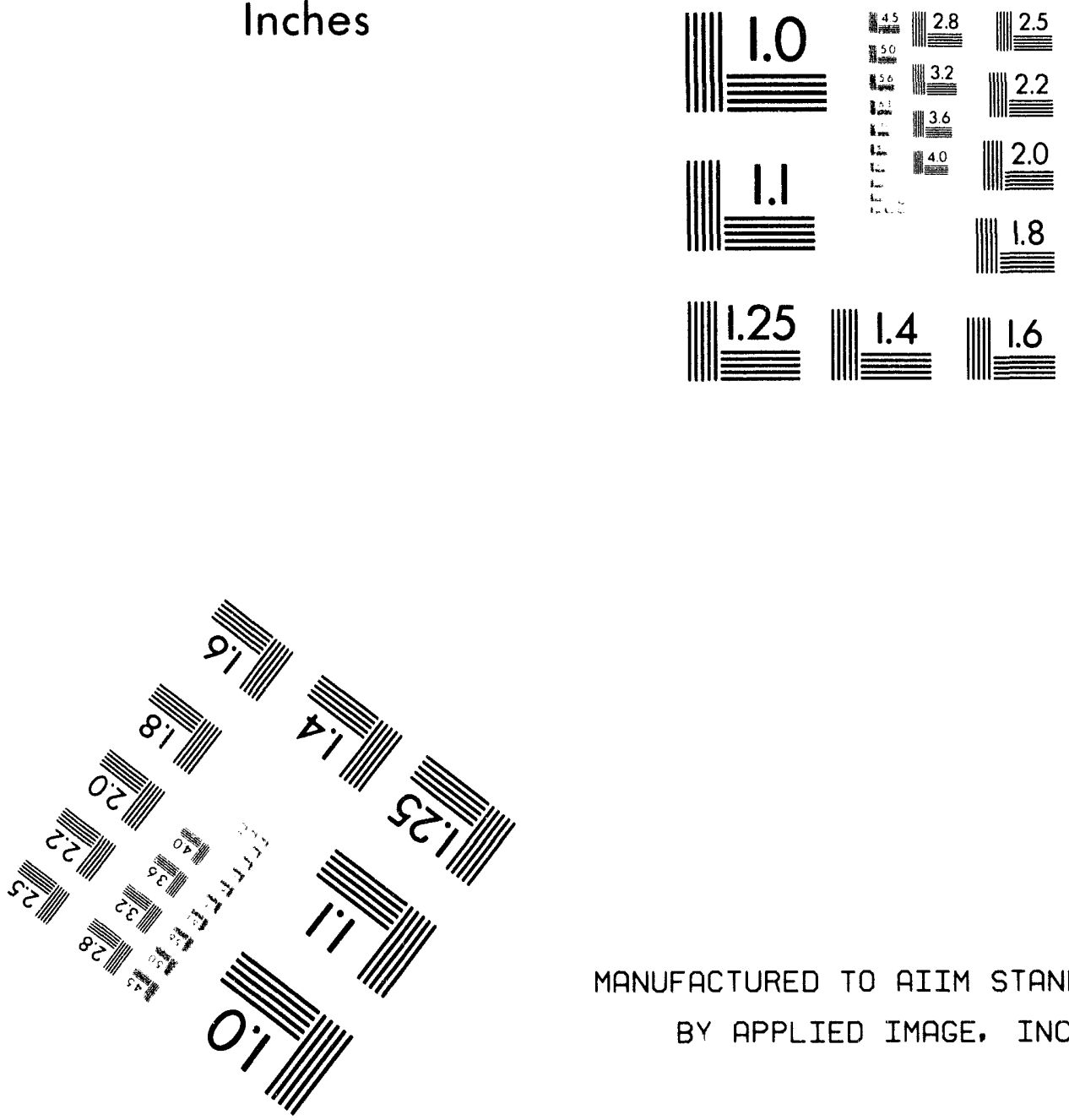

MANUFACTURED TO AIIM STANDARDS

BY APPLIED IMAGE, INC.

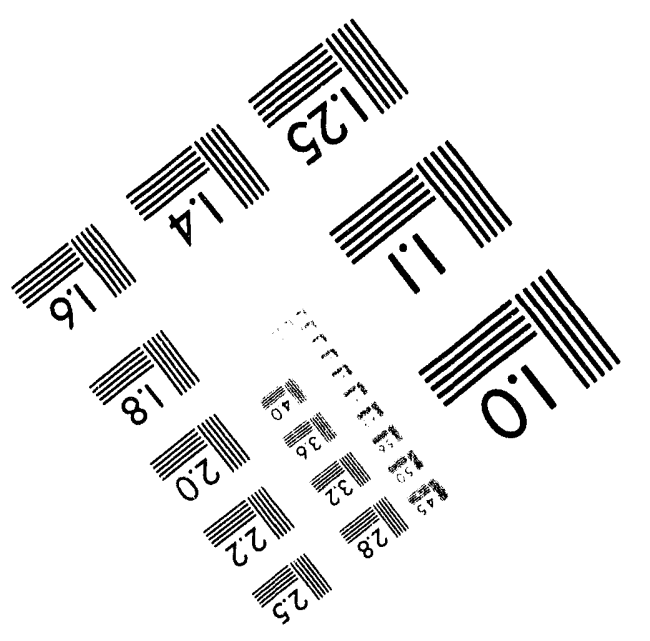




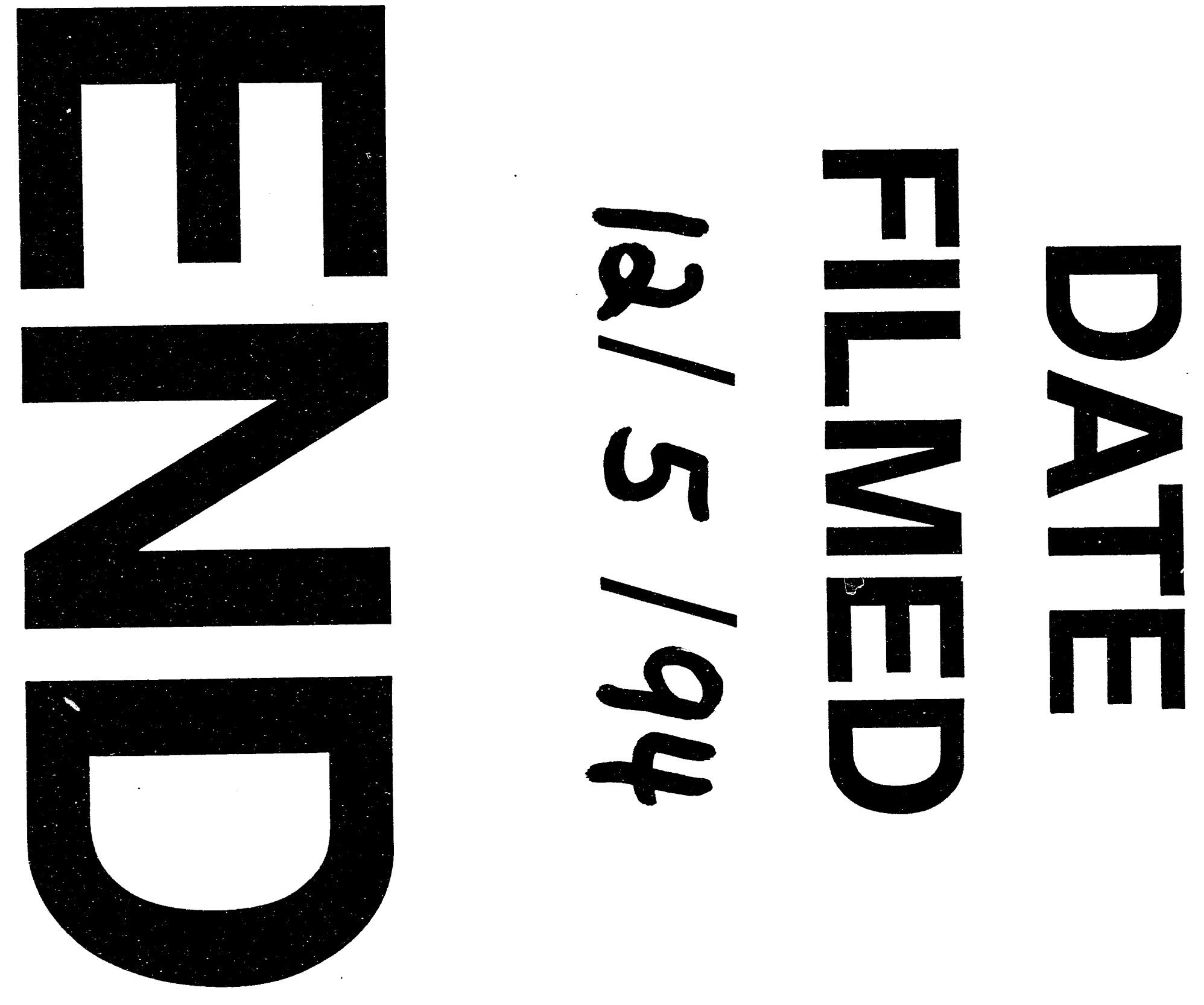